\title{
Programa de resgate do patrimônio fossilífero da UHE Teles Pires, MT: estudo de caso
}

\author{
Programa de rescate del património fossilífero de la UHE Teles \\ Pires, MT: estúdio de caso
}

Rescue Program of salvage of fossiliferous heritage of Teles
Pires hydroelectric power plant (MT, Brazil): case study

Roberto Iannuzzi

roberto.iannuzzi@ufrgs.br

Universidade Federal do Rio Grande do Sul, UFRGS, Porto Alegre, RS

Fernando Erthal

fernando.erthal@ufrgs.br

Universidade Federal do Rio Grande do Sul, UFRGS, Porto Alegre, RS

Erika Marion Robrahn-González

erika@documentocultural.net

Documento Antropologia e Arqueologia Ltda.

William Vieira Gobo

williamgobo@hotmail.com

Universidade Federal do Rio Grande do Sul, UFRGS, Porto Alegre, RS

Resumo: São apresentados atividades e os resultados gerais obtidos pelo Programa de Investigação, Monitoramento e Salvamento do Patrimônio Fossilífero, proposto para a UHE Teles Pires. Foi coletada uma boa quantidade de macrofósseis vegetais e raros moldes de invertebrados conchíferos nos depósitos de terraços do rio Teles Pires. Em termos de microfósseis, detectou-se a presença de espículas de esponjas de água doce. Conforme as datações absolutas efetivadas na base dos depósitos, sugeriu-se que a deposição dos atuais terraços do rio Teles Pires se iniciaram há, pelo menos, 66.000 anos atrás. A partir da realização do programa duas recomendações são endereçadas a futuros programas de salvamento paleontológico nesse tipo de empreendimento: (i) todos os terrenos contendo rochas sedimentares que se tornarão permanentemente inacessíveis devem ser prospectados na busca por fósseis (diferentemente do recomendado na proposta inicial que restringia o salvamento à área da embarramento); (ii) sempre deve haver coletas e análises para a extração de possíveis microfósseis, pois a presença de microfósseis em depósitos sedimentares tem sido amplamente negligenciada nas propostas de salvamento paleontológico apresentadas aos órgãos competentes, porém, este patrimônio de escala microscópica merece também nossa atenção e salvaguarda dada a sua relevância para reconstruções paleombientais e climáticas.

Palavras chave: Patrimônio paleontológico, salvamento paleontológico, Região Norte do Brasil.

Resumen: Se presentan las actividades y los resultados generales obtenidos por el Programa de Investigación, Monitoreo y Salvamento del Patrimonio Fosilífero, 
propuesto para la Usina Hidroeléctrica Teles Pires. Se recogió una buena cantidad de macrofósiles vegetales y raros moldes de invertebrados conchíferos en los depósitos de terrazas del Río Teles Pires. En términos de microfósiles, se detectó la presencia de espículas de esponjas de agua dulce. Conforme a las fechas absolutas efectivas en la base de los depósitos, se sugirió que la deposición de las actuales terrazas del río Teles Pires se inició hace, por lo menos, 66.000 años atrás. A partir de la realización del programa dos recomendaciones se dirigen a futuros programas de salvamento paleontológico en ese tipo de emprendimiento: (i) todos los terrenos que contengan rocas sedimentarias que se vuelvan permanentemente inaccesibles deben ser explorados en la búsqueda de fósiles (a diferencia de lo recomendado en la propuesta inicial que restringía el rescate al área del canal del río junto a la represa); ii) siempre debe haber colectas y análisis para la extracción de posibles microfósiles, pues la presencia de microfósiles en depósitos sedimentarios ha sido ampliamente descuidada en las propuestas de salvamento paleontológico presentadas a las agencias competentes, sin embargo, este patrimonio de escala microscópica merece también nuestra atención y salvaguardia dada su relevancia para las reconstrucciones paleoambientales y climáticas.

Palabras-clave: Património paleontológico, rescate paleontológico, región del norte de Brasil.

Abstract: In this paper, it has been presented the activities and general results from the Fossiliferous Heritage Research, Monitoring and Rescue Program performed in the Hydroelectric Power Plant Teles Pires. A good number of vegetal macrofossils and rare molds of conchiferous invertebrates were collected in the terraces deposits of the Teles Pires River. In terms of microfossils, the presence of spicules of freshwater sponges was detected. According to the absolute dating made at the base of the deposits, it was suggested that the deposition of the current sedimentary terraces of the Teles Pires river began at least 66,000 years ago. From the realization of the program two recommendations are addressed to future programs of paleontological rescue in this type of enterprise: (i) all land containing sedimentary rocks that will become permanently inaccessible should be prospected for fossil (unlike the one recommended in the initial proposal which restricted the salvage to the area of the river channel near the dam); ii) there must always be collections and analyzes for the extraction of possible microfossils, since the presence of microfossils in sedimentary deposits has been largely neglected in the proposals of paleontological rescue presented to the competent agencies, but this heritage of microscopic scale also deserves our attention and safeguard given its relevance to paleoenvironmental and climatic reconstructions. Key words: Paleontological heritage, paleontological rescue, North Region of Brazil.

\section{INTRODUÇÃO}

Segundo Sharples (2002, p.2), “a Geoconservação objetiva a preservação da diversidade natural (ou geodiversidade) de significativos aspectos e processos geológicos (substrato), geomorfológicos (formas de paisagem) e de solo, por meio da manutenção da evolução natural desses aspectos e processos". Resumidamente, a geoconservação tem por objetivo geral a utilização e gestão sustentável da geodiversidade (BRILHA, 2005). Deste modo, Brilha (2005) sugere seis etapas para o estabelecimento de estratégias de geoconservação do geopatrimônio, enquanto Gray (2008) lista 12 métodos de geoconservação, a fim de aplicá-los na gestão/manejo dos diferentes tipos de geossítios existentes. Porém, assim 
como acontece com outros tipos de patrimônio, a geodiversidade encontra-se ameaçada em diversos graus e escalas. Por isso, tão importante quanto identificar, caracterizar e valorar os geossítios representativos da Geologia de uma dada região, está o reconhecimento dos vários tipos de ameaças que acometem a geodiversidade (GRAY, 2004; BRILHA, 2005). Para Brilha (2005), o desenvolvimento de obras e estruturas é uma das principais ameaças à geodiversidade. A abertura de estradas/rodovias e a construção de edificações de grande envergadura e barragens estão entre os tipos de intervenções que produzem maiores impactos negativos sobre a geodiversidade.

Entre os métodos de geoconservação propostos por Gray (2008), ele cita a escavação e envio do material a museus (excavation/curation) para estudos e exposição ao público como um método adequado para ser aplicado, especialmente, nos casos onde há conteúdo paleontológico e/ou mineralógico envolvido. Neste sentido, o resgate paleontológico por meio de coleta de materiais pode ser compreendido como uma estratégia de geoconservação que se aplica como uma ação mitigadora naquelas situações onde o patrimônio fossilífero local será inevitavelmente destruído ou ficará inacessível devido à implantação de um empreendimento. Isto é necessariamente verdadeiro para aqueles empreendimentos nos quais parte substancial do depósito fossilífero será removido durante a intervenção ou ficará submerso e/ ou fora de alcance das pessoas - pesquisadores, interessados, autoridades, etc. Nestas situações, o resgate (com coleta) configura-se em uma alternativa possível para preservar parte do conteúdo fossilífero e da informação geológica associada ao depósito alvo da inevitável intervenção promovida pelo empreendimento. Outra estratégia de geoconservação possível nestes casos é a obtenção de moldes em alta resolução das superfícies de afloramentos com interesse paleontológico que possibilitam a reprodução dos mesmos em laboratórios ou exibições em museus (EDWARDS, WILLIAMS, 2011; WILLIAMS, EDWARDS, 2013). Apesar de este método ser considerado como um tipo de resgate paleontológico (sem coleta de material), ele é empregado apenas em certas situações específicas, onde se deseja preservar o relevo das superfícies de afloramentos que possuem alto risco de degradação, sem causar danos aos mesmos.

Apesar dos fósseis e os sítios paleontológicos serem considerados (i) bens da União Federal, pelo Decreto-Lei № 4.146, outorgado em 04/03/1942 (ratificado pela Lei № 8.176 de 08/02/1991), e (ii) Patrimônio Cultural da Nação, pela Constituição Federal de 1988 (arts. 20, 23, 24, 216), não existe requisito legal para que ocorram salvamentos paleontológicos em empreendimentos, mesmo naqueles de grande vulto, nos moldes do existente para o Patrimônio Arqueológico. Porém, no Parecer No 107, de 23/04/2010, o DNPM concluiu que: "XIII. Deve-se buscar com urgência um entendimento entre DNPM, IPHAN [Instituto do Patrimônio Histórico e Artístico Nacional] e órgãos ambientais federais competentes para elaboração de procedimento comum e em regime de cooperação técnica com vistas à proteção e a preservação dos fósseis e sítios de relevante valor paleontológico".

Assim, o P.32 - Programa de Investigação, Monitoramento e Salvamento do Patrimônio Fossilífero, proposto para a Usina Hidroelétrica (UHE) Teles Pires, visou não tão somente cumprir a legislação vigente e recomendações dos órgãos públicos, mas também atender ao condicionante $N^{\circ} 2.2$ da Licença Prévia N³86/2010, que estabeleceu “Incluir no Projeto 
Básico Ambiental o Programa de Investigação, Monitoramento e Salvamento Paleontológico em acordo com o Departamento Nacional de Produção Mineral (DNPM)" (IANNUZZI, ERTHAL, 2014, p. 3). Neste contexto, o P.32 procurou antecipar-se às diretrizes contidas no Projeto de Lei $N^{\circ} 7420 / 2010$, proposto pelo Senador Pedro Simon e atualmente em tramitação no Senado Federal (que "Dispõe sobre a proteção ao patrimônio fossilífero, em conformidade com o art. 216, inciso V, da Constituição Federal, e dá outras providências"), bem como resguardar a preocupação frente à proteção desse tipo de patrimônio, interposta por diversos órgãos públicos federais (DNPM, IBAMA, ICMBio), de representações da comunidade científica (Sociedade Brasileira de Paleontologia - SBP, Sociedade para o Progresso da Ciência - SBPC, antiga Comissão Brasileira de Sítios Geológicos e Paleobiológicos - SIGEP) e Instituições Federais de Ensino Superior e Pesquisa (IFESs).

O objetivo da presente contribuição é apresentar as atividades realizadas e os resultados obtidos pela execução do P.32 junto à implementação da UHE Teles Pires, na divisa dos estados de Mato Grosso e Pará, com intuito de que estes possam nortear ações futuras em empreendimentos semelhantes. No entanto, não se deve ignorar o fato de que a publicação dos resultados corresponde à parte final do processo de salvamento, configurando-se na oportunidade de dar conhecimento da existência e execução do programa (P.32) junto à comunidade científica, bem como à sociedade civil.

\section{METODOLOGIA}

Ainda que os estudos paleontológicos elaborados na fase de EIA-RIMA tenham se mostrado pouco profícuos quanto à presença do registro fossilífero, de fato existiam relatos sobre as ocorrências paleontológicas associadas à megafauna pleistocênica (paleomastofauna) provenientes da área de garimpagem de ouro, situada à jusante do eixo da barragem da UHE Teles Pires. Uma das questões básicas para a região dizia respeito à escassez de investigações paleontológicas sistemáticas, o que de fato apontava para a necessidade do aprofundamento das pesquisas geológicas e paleontológicas na bacia do alto Teles Pires. Deste modo, o P.32 foi dividido em três etapas:

$1^{a}$. Educação Patrimonial - com a realização de cursos de capacitação técnica em Paleontologia e palestras educativas com Tema de Educação Patrimonial para Paleontologia para funcionários da UHE Teles Pires e comunidades dos municípios de Paranaíta e Alta Floresta afetadas pelo empreendimento;

$2^{\mathrm{a}}$. Intervenções de coleta paleontológica in loco realizadas na Área Diretamente Afetada (ADA) do empreendimento, que constitui o salvamento propriamente dito (Fig. 1);

$3^{\mathrm{a}}$. Transporte, curadoria e guarda do material científico em instituição recomendada pelo DNPM. 
Figura 1. Mapa geológico simplificado da área de estudo. A. Sítio 111-3 (66 +/- 9,5 ka; LOE); B. Sítio 004 (3,5 a 3,6 ka; AMS- 14C); C. Concreções ferruginosas contendo impressões foliares; D. Sítio 105 (10,17 a 10,24 ka; AMS- 14C), E. Sítio 040 (8,5 +/- 1,4 ka; LOE); F. Sítio 022 (16 +/- 2,03 ka; LOE); G. Sítio 019 (22,6 a 23,3 ka; AMS-14C). A real distribuição de sedimentos cenozoicos associados à deposição do rio Teles Pires está subestimada.

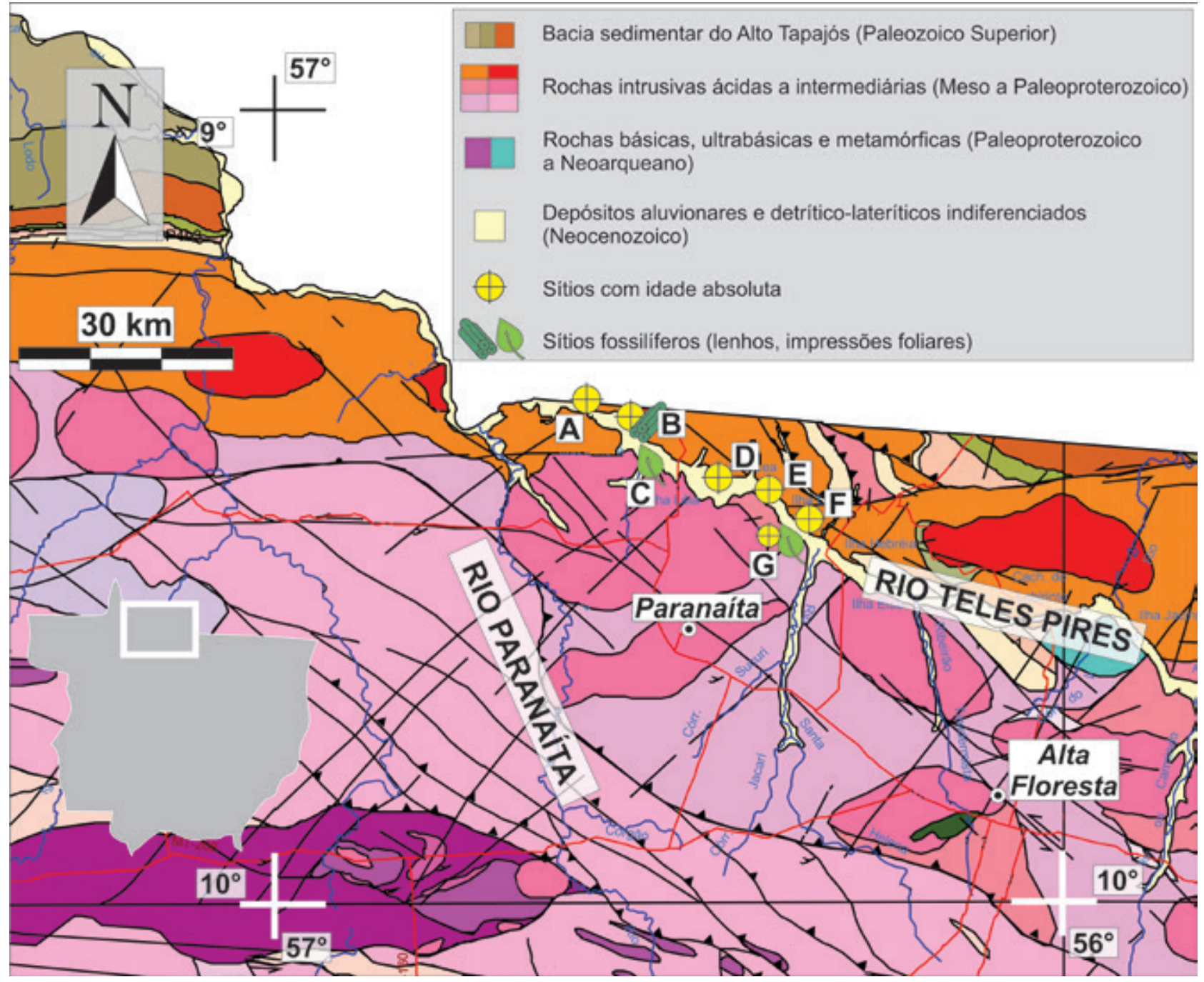

Fonte: mod. de Lacerda Filho et al. (2004).

Durante a etapa de avaliação, a qual incluiu trabalhos de campo e entrevistas com ex-garimpeiros, ficou claro que o setor de maior potencial paleontológico não era somente o canteiro de obras em si (i.e., barramento), mas também a área destinada ao futuro reservatório, ambos inseridos na ADA, além de trechos dos municípios de Paranaíta/MT e Jacareacanga/PA, incluídos na Área de Influência Direta (AID). A pesquisa realizada na área de interesse paleontológico se deu por meio de deslocamentos via fluvial ou terrestre e caminhamento ao longo das margens dos rios Teles Pires e Paranaíta, onde houve (i) a recuperação de blocos de sedimento contendo impressões e compressões de plantas (Fig. 2A-B), (ii) a investigação intensiva das concreções ferruginosas em rejeitos de draga (Fig. 2C-D), (iii) a recuperação de blocos de sedimento contendo lenhos carbonificados (Fig. 2EF), (iv) a coleta intensiva de blocos de argila com estrutura laminada contendo impressões 
de plantas (Fig. 3A), (v) a recuperação de testemunhos horizontais e amostras para datação absoluta (termoluminescência e carbono-14) (Fig. 3B), (vi) a recuperação de testemunhos verticais (Fig. 3C-D) e (vii) de amostras para análise micropaleontológica (palinológica e organismos silicosos) (Fig. 3E), (viii) o detalhamento de perfil estratigráfico (Fig. 3F), em locais considerados chave para o estabelecimento de correlações estratigráficas e, por conseguinte, de um arcabouço estratigráfico da área de estudo.

Figura 2. A-B. Clastos de argila ricos em matéria orgânica, onde são encontradas impressões de folhas; C-D. Coleta de concreções ferruginosas em rejeitos de draga; E-F. Envolvimento em gesso de blocos de sedimento contendo lenhos carbonificados.
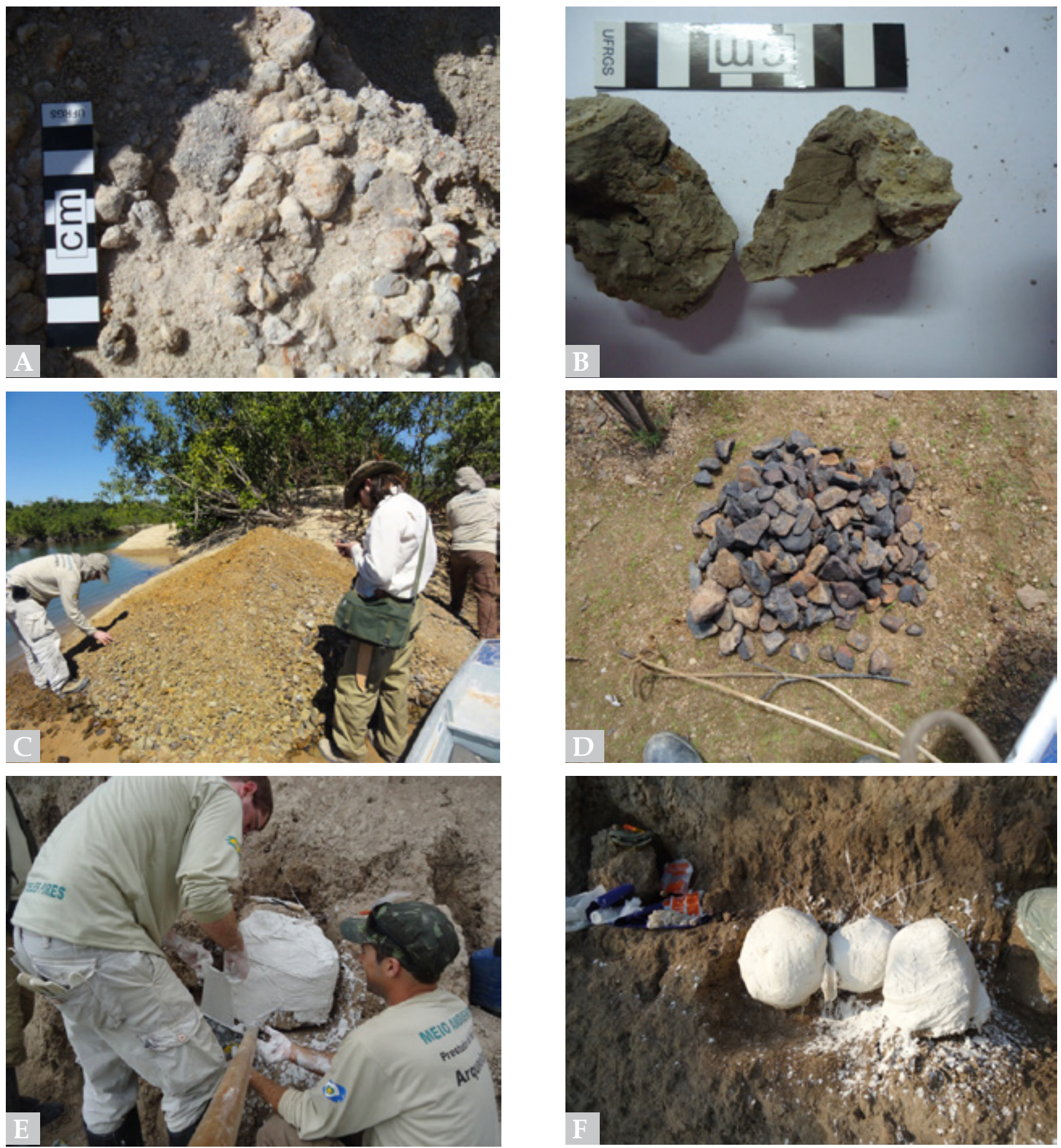

Fonte: mod. de Iannuzzi, Erthal (2014). 
Figura 3. A. Coleta de impressões de folhas em argila laminada; B. Coleta de amostra horizontal para datação absoluta; C-D. Coletas de testemunhos verticais rasos; E. Delimitação de níveis para coleta de amostras para análise micropaleontológica; F. Detalhamento estratigráfico, com coleta de testemunho horizontal na base do nível 01.
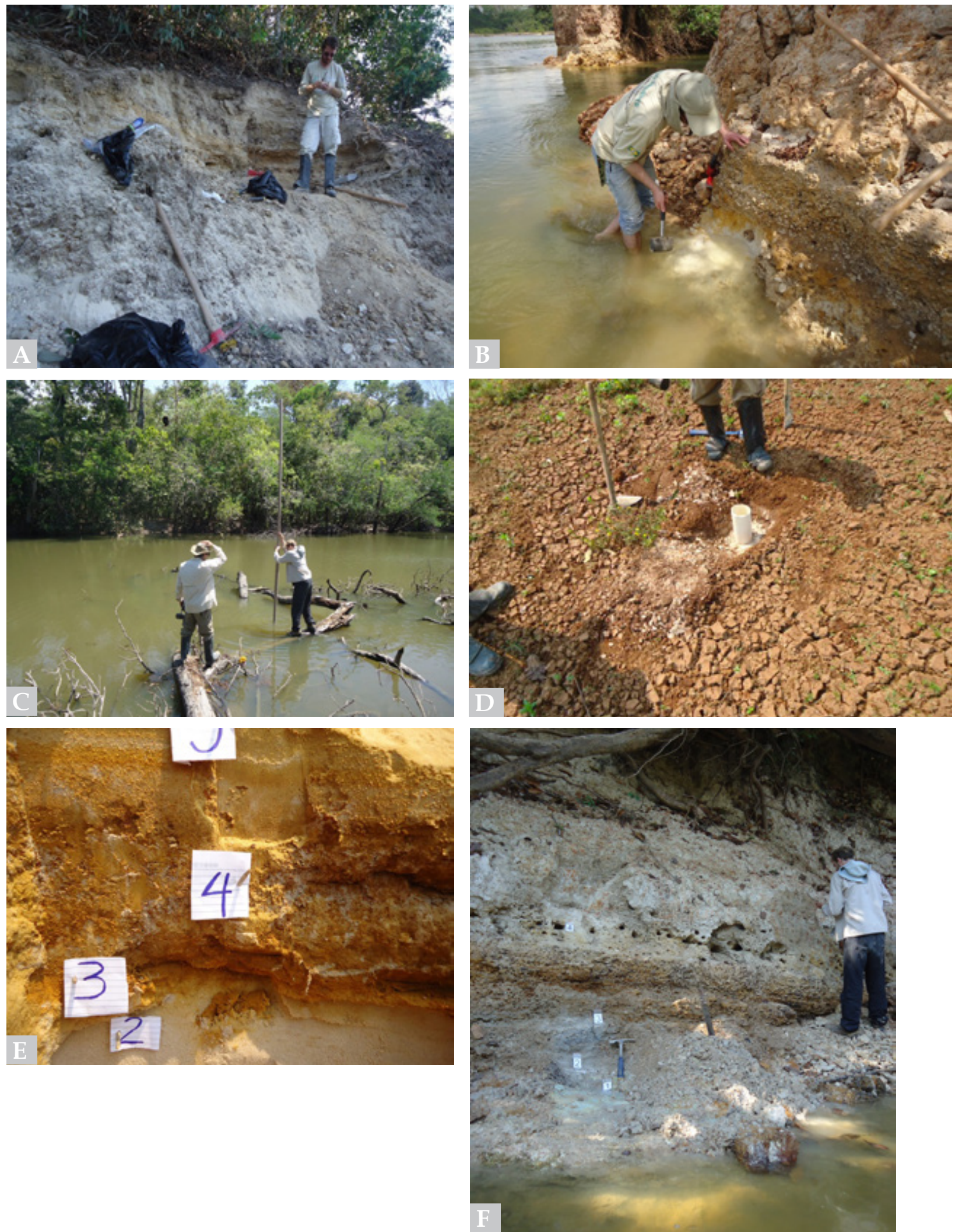

Fonte: mod. de Iannuzzi, Erthal (2014). 
A fim de auxiliar nas correlações estratigráficas dos perfis obtidos em afloramento, foram requisitados os perfis geológicos obtidos das sondagens de poços feitos para monitoramento do nível freático (i.e., piezômetros), realizados pelo empreendimento ao longo das margens do rio Teles Pires.

Dentro do tempo disponível para realizar o salvamento paleontológico, antes que a área do reservatório viesse a ser inundada, foram realizadas duas campanhas de campo (2012-2013), concentradas nos meses de seca (agosto-setembro), quando há queda no nível de base dos rios da região. As etiquetas de Pesquisa Paleontológica destinaram-se a identificar o material paleontológico que foi guardado no Laboratório de Arqueologia e Paleontologia/Documento, UHE Teles Pires, bem como o material que foi enviado para UFRGS por meio de doação. Já etiquetas de Análise Paleontológica destinaram-se a identificar o material que seguiu para análise (micropaleontológica, datação absoluta, etc.) por terceiros. O Departamento de Paleontologia e Estratigrafia (DPE) da Universidade Federal do Rio Grande do Sul (UFRGS) foi determinado como fiel depositário do material fóssil coletado. Para a Curadoria, foram criados dois tipos de etiquetas do acervo paleontológico: Pesquisa Paleontológica e Análise Paleontológica.

Para datação absoluta usando carbono-14 foi utilizada a técnica de Espectrometria de Massa Acelerada (Accelerated Mass Spectrometry - AMS ${ }^{14} \mathrm{C}$ ), realizada pelos laboratórios da Beta Analytic, em Miami, Flórida, E.U.A. As duas amostras usadas para datação eram constituídas por fragmentos de caules e folhas extraídos do interior de clastos de lamito retrabalhados, e uma amostra de lenho incarbonizado, todos coletados in situ. A datação absoluta de amostras de natureza inorgânica utilizou testemunhos sedimentares de areia, empregando a técnica de Luminescência Oticamente Estimulada (LOE, ou em inglês Optically Stimulated Luminescence - OSL), em três localidades distintas (pontos P022, P040 e P111-3). Essas análises foram realizadas no laboratório da empresa Datação Comércio \& Prestação de Serviços, localizada em São Paulo.

\section{RESULTADOS E DISCUSSÃO}

Uma das primeiras atividades estabelecida no P.32 foi a execução de palestras e oficinas de Paleontologia para a população, autoridades e os envolvidos na obra da UHE Teles Pires. Numa primeira etapa, foi feita uma apresentação de esclarecimento sobre a Paleontologia, seus objetivos e o salvamento paleontológico que seria realizado na ADA da UHE Teles Pires para o prefeito, alguns secretários municipais e professores da rede pública do município de Paranaíta. Durante o ano de 2012, foram proferidas palestras e exposições sobre a Paleontologia aos estudantes e professores de todas as escolas públicas de ensino básico (fundamental e médio), localizadas em Paranaíta. Estas últimas foram executadas juntamente com aquelas de Patrimônio Cultural, Histórico e Arqueológico. Os conteúdos apresentados se encontram disponíveis no endereço http://documentoculturaltelespires.ning.com/. 
Mais de uma centena de pontos foi identificada como interessante do ponto de vista paleontológico. Infelizmente, o leito do rio Teles Pires, na área do barramento, não apresentou fósseis preservados, nem mesmo no interior das chamadas 'panelas' ou 'cacimbas' formadas pela erosão das correntes sobre a superfície das rochas de origem magmática e/ou metamórfica (Fig. 4A-B). Os principais afloramentos contendo algum tipo de fóssil foram encontrados nos terraços do rio Teles Pires e eram constituídos de lama depositada em ambientes de planície de inundação.

Foram detalhados perfis estratigráficos em pelo menos 30 pontos (Fig. 5A-B). Cabe destacar aqui que métodos para obtenção de moldes de afloramentos completos não foram nem sequer aventados no presente caso, pois eles têm sido empregados quando há interesse na análise dos icnofósseis preservados nos planos de acamamento, tais como trilhas de deslocamento (pegadas, apêndices, etc.), pistas ou escavações, bem como impressões em baixo relevo deixadas por partes corpóreas de organismos da Fauna de Ediacara, por exemplo (EDWARDS, WILLIAMS, 2011; WILLIAMS, EDWARDS, 2013). Os afloramentos-alvo das análises não apresentaram feições superficiais excepcionais ou icnofósseis relevantes que justificassem a sua reprodução para posteridade; o registro via imagens fotográficas, descrição de perfis e amostragem das fácies e dos fósseis foi considerado suficiente pela equipe como método de geoconservação do patrimônio. Além disso, a elaboração de moldes em látex ou silicone não é adequada às superfícies úmidas ou colonizada por líquens (WILLIAMS, EDWARDS, 2013), uma situação freqüente em afloramentos da região amazônica. Por fim, os materiais de melhor resolução são relativamente caros e as exposições localizadas em áreas úmidas precisam, por vezes, serem preparadas com semanas de antecedência (WILLIAMS, EDWARDS, 2013). Por todo o exposto, os métodos que envolvem a aquisição de réplicas dos afloramentos não parecem aconselháveis para os projetos de resgate em áreas de climas bastante úmidos, pois o período de acesso aos afloramentos, ao final das estações de seca, é curto e o número de campanhas costuma ser reduzido, de duas a três, antes que as exposições não estejam mais acessíveis. 
Figura 4. A. Vista da face jusante da ensecadeira de montante, onde se nota a porção exposta do leito do rio Teles Pires; B. Vista do recinto 1, com o leito totalmente exposto, a partir da ensecadeira central, que mostra o mesmo composto em grande parte por blocos e matacões.
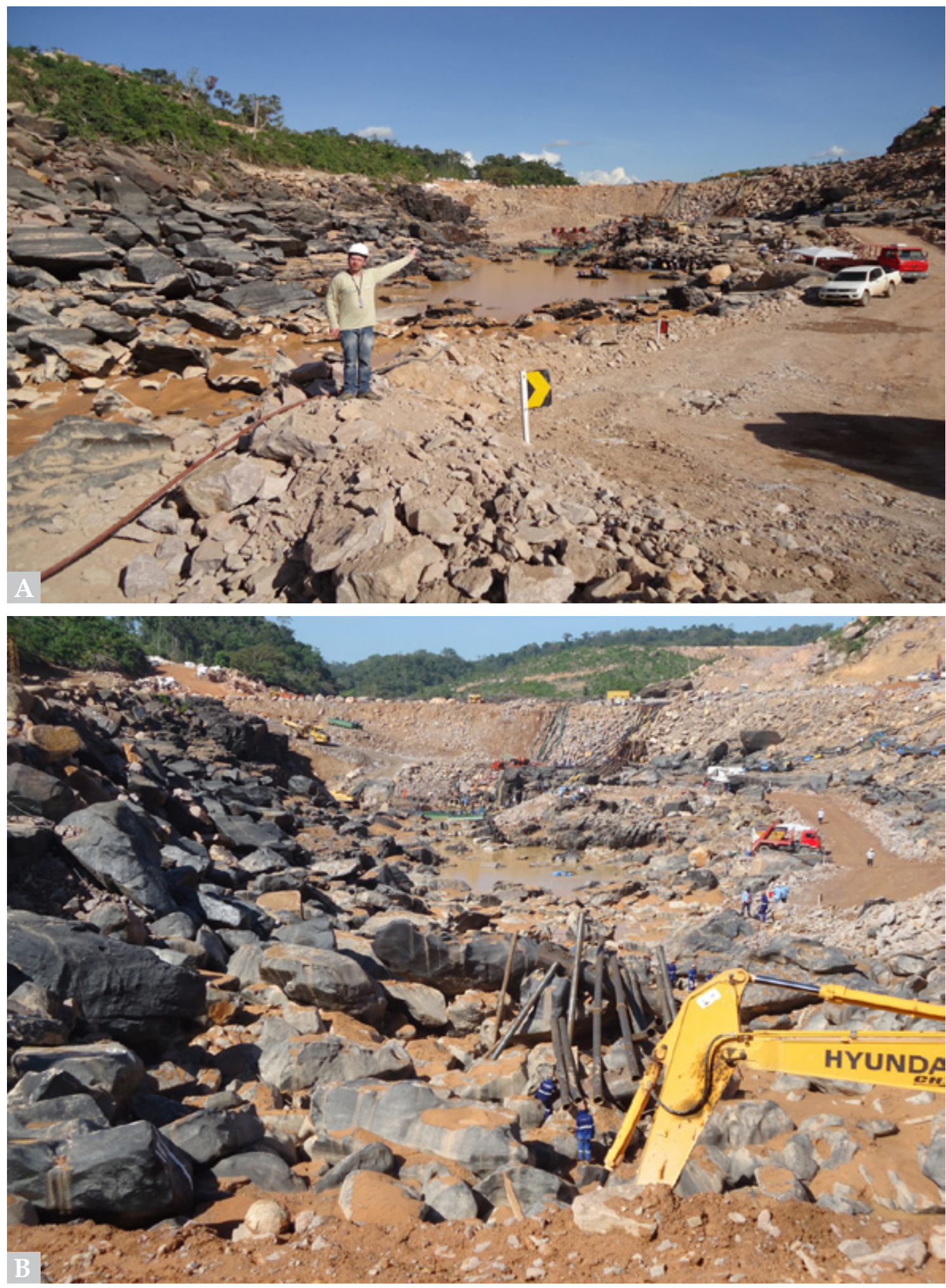

Fonte: mod. de Iannuzzi, Erthal (2014). 
Figura 5. A. Correlação entre o perfil geológico dos piezômetros 14 e 15 e os perfis estratigráficos obtidos no afloramento P019, onde se nota a presença de folhas fósseis; B. Correlação entre o perfil geológico dos piezômetros 12 e 08 e os perfis estratigráficos obtidos nos afloramentos P108 e P153, onde se observa a presença de caules carbonificados em P153.
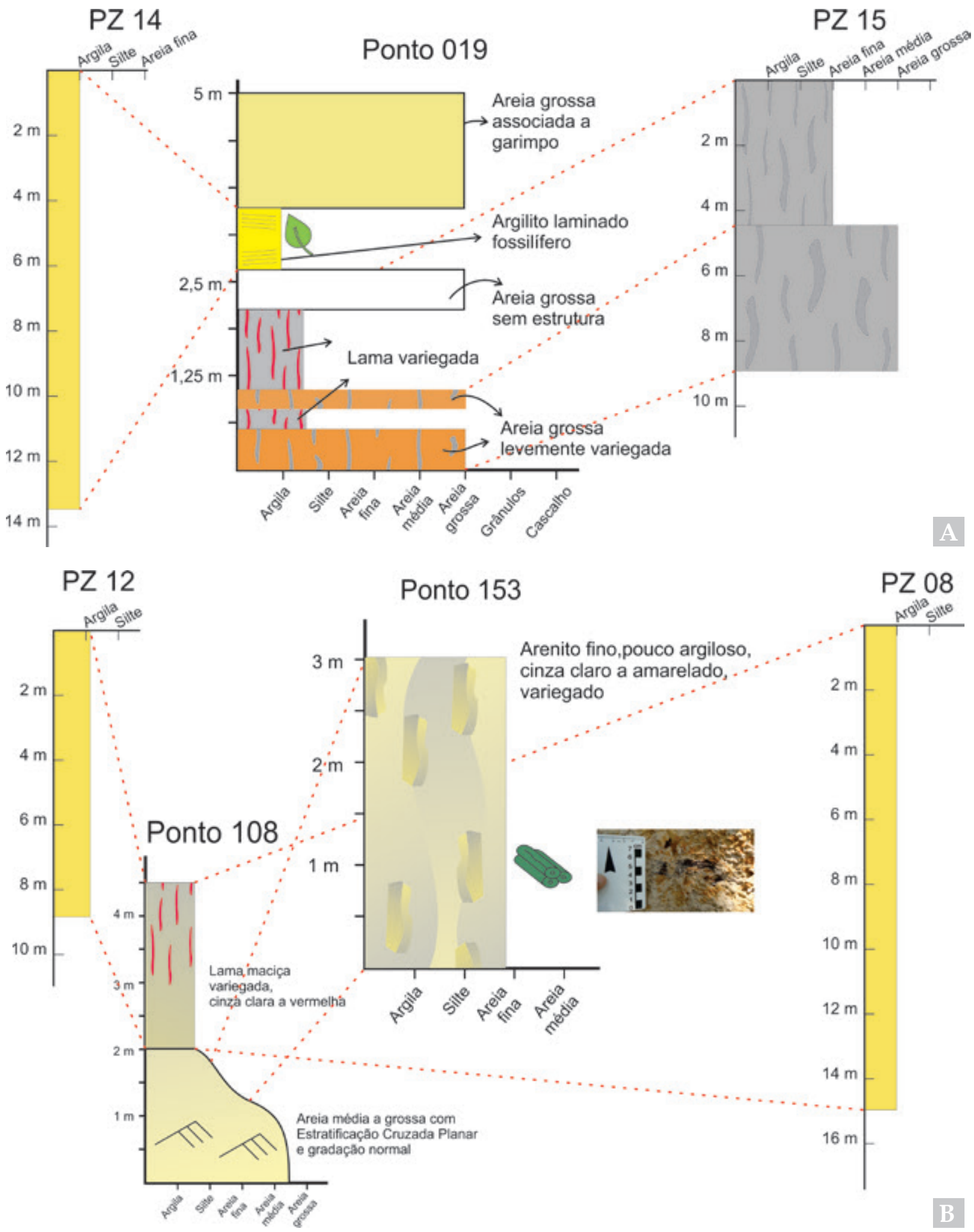

Fonte: mod. de Iannuzzi, Erthal (2014). 
No geral, os macrofósseis encontrados corresponderam a espécimes constituídos predominantemente por restos e vestígios paleobotânicos, exceto pela obtenção de uns poucos moldes de moluscos (gastrópodes e bivalves). Foram recolhidas mais de 200 amostras de clastos de lama retrabalhados contendo em seu interior abundantes restos de partes foliares (Fig. 6A). Foi identificado argilito com estrutura laminada, indicativo de ambiente parálico (lacustre), que se mostrou ricamente fossilífero, contendo várias impressões vegetais de boa qualidade (Fig. 6B). Coletou-se cerca de 200 quilos deste argilito para posterior preparação em laboratório. Também foram recolhidas cerca de 120 amostras de lenhos carbonificados nos terraços, sendo que dez retiradas em bloco de gesso (Fig. 6C). Por fim, foram coletadas cerca de 800 concreções ferruginosas, de natureza ainda indeterminada, contendo em seu interior impressões de partes vegetais, principalmente folhas, em perfeito estado de preservação (Fig. 6D), e raros moldes de bivalves (Fig. 6E).

Em termos de microfósseis, detectou-se conteúdo considerável de espículas de esponjas bem formadas em apenas duas das amostras oriundas das margens do rio Teles Pires, das 98 amostras coletadas. Não foi detectado nenhum microfóssil de parede orgânica (palinomorfos) nas preparações realizadas, porém há um testemunho raso que poderá ser utilizado para análises micropaleontológicas adicionais.

Três amostras de material paleontológico (restos vegetais) foram preparadas para datação absoluta com carbono-14 (AMS ${ }^{14} \mathrm{C}$ ) e três testemunhos sedimentares de areia para datação segundo a técnica de Luminescência Oticamente Estimulada (LOE) (Fig. 6F). As amostras vegetais apresentaram idades calibradas entre 22.580 e 23.290 anos, 10.170 e 10.240 anos e 3.560 e 3.690 anos AP (antes do presente). As idades obtidas por LOE foram as seguintes: na localidade 022 , idade média de $16.000 \pm 2.030$ anos; na localidade 040 , idade média de $8.500 \pm 1.400$ anos; na localidade 111-3, idade média de $66.000 \pm 9.930$ anos. Enfatiza-se que as amostras submetidas à técnica de LOE foram recuperadas de níveis basais nos terraços do rio Teles Pires, logo acima do nível base do rio na estação seca. Assim, pode-se afirmar com certeza que, dentro da área estudada (área do reservatório da UHE Teles Pires), o rio Teles Pires deposita sedimentos que formam os atuais terraços desde há, pelo menos, 66.000 anos. 
Figura 6. A. Clastos de argila ricos em matéria orgânica, onde são encontradas impressões de folhas; B.

Impressão de folha encontrada na argila laminada (P019); C. Fragmentos de lenhos carbonificados; D. Impressão de folha encontrado no interior de uma concreção ferruginosa; E. Contra-molde de um bivalve encontrado em uma concreção ferruginosa; F. Testemunhos horizontais obtidos para datação por termoluminescência (LOE).
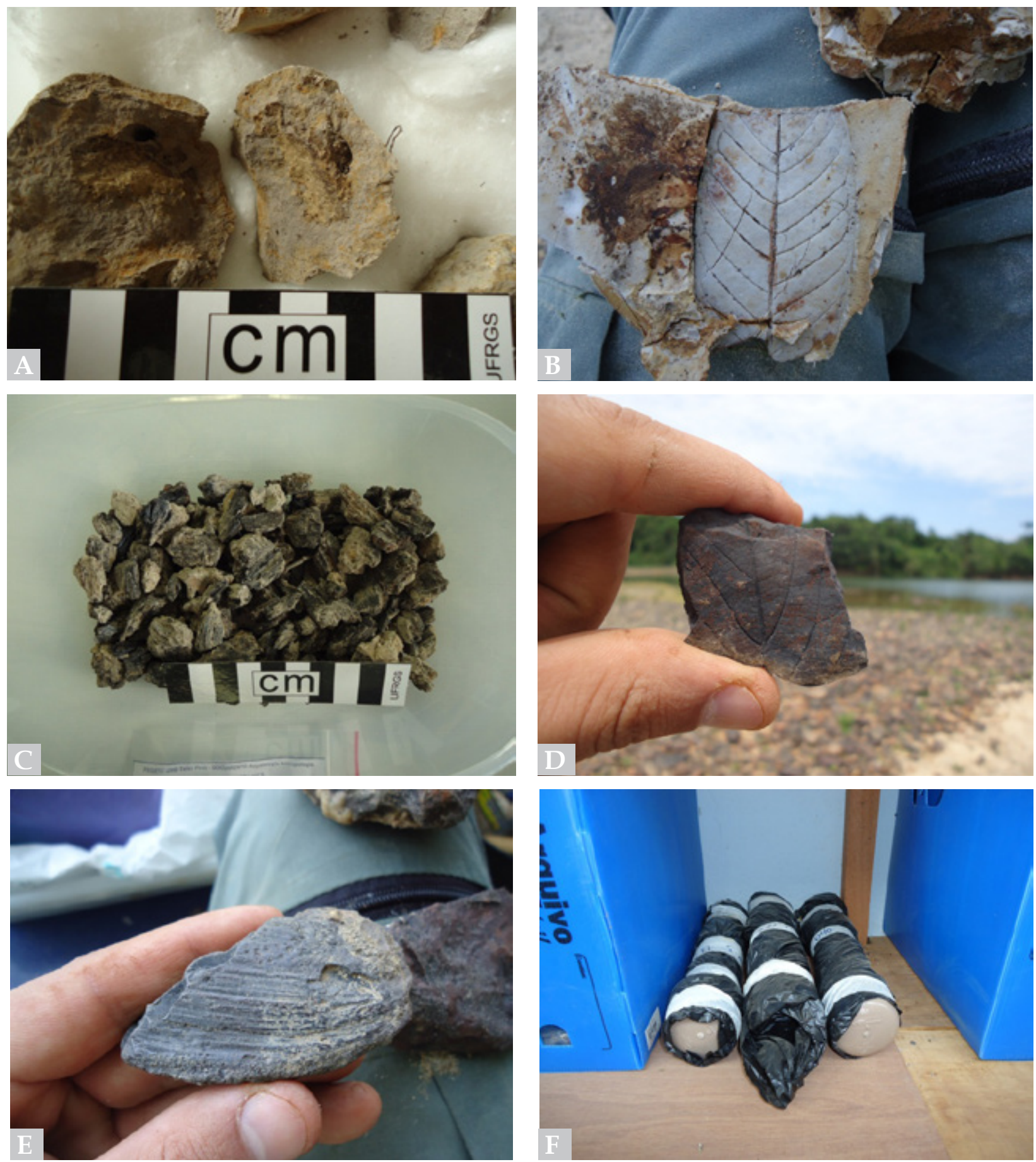

Fonte: mod. de Iannuzzi, Erthal (2014). 


\section{CONCLUSÕES E RECOMENDAÇÕES}

Pode-se salientar que as atividades desenvolvidas aqui com o intuito de atender os objetivos e metas propostos no P.32, foram um sucesso, tendo em vista que boa quantidade de diferentes tipos de fósseis, em sua maioria de plantas, foram coletados e salvaguardados.

As atividades procuraram não só localizar e coletar fósseis, mas também valorar cientificamente os elementos da geodiversidade, como um patrimônio $e x$-situ, devidamente dimensionado e aferido por meio do levantamento de perfis e amostragens sedimentológicas das principais seções expostas, recuperação de testemunhos e recuperação de amostras para datação absoluta, uma vez que toda a área analisada da ADA foi, como previsto, permanentemente encoberta pelo preenchimento do reservatório. Assim um capítulo [ou mais] da história do Quaternário da região está apropriadamente registrado e protegido, através das ações ligadas ao resgate do acervo paleontológico. Neste sentido, reitera-se aqui a importância dos programas de salvamento paleontológico em obras no âmbito específico da geoconservação.

Por fim, cabe salientar dois diferenciais alcançados pela equipe em relação aos objetivos e metas propostos originalmente no P.32. Ao contrário do que foi recomendado, optou-se por realizar um significativo esforço prospectivo na Área do Reservatório, previamente descartada nos estudos preliminares, devido ao seu contexto geológico desfavorável, mas de onde proveio todo o material fóssil recuperado. A área do canteiro de obras junto ao barramento da UHE Teles Pires, estabelecida como a área-alvo do salvamento paleontológico pelo P.32, não forneceu nenhum fóssil após o monitoramento. A decisão de incluir a Área do Reservatório, abrangendo a prospecção das margens dos rios Teles Pires e Paranaíta e depósitos associados às suas respectivas planícies de inundação, foi estabelecida pela equipe durante a etapa de avaliação, a partir dos relatos feitos nas entrevistas com ex-garimpeiros e da experiência prévia dos membros com depósitos fluviais. Portanto, fica uma recomendação endereçada a futuros programas de salvamento paleontológico no sentido de que sempre que houver depósitos sedimentares, mesmo que superficiais (pouco espessos) e representados por sedimentos inconsolidados e relativamente jovens (quaternários), deverá haver obrigatoriamente necessidade de prospecção visando o encontro de fósseis.

O segundo ponto a ser ressaltado, refere-se ao interesse da equipe em efetuar coletas de amostras para preparação por busca de microfósseis nos depósitos sedimentares analisados. Tais preparações forneceram, até o momento, resultados positivos para a presença de espículas de esponjas de água doce. Porém, há amostras ainda em análise (palinológica) e outras tantas disponíveis para preparações futuras que serão efetuadas via encaminhamentos para pesquisadores interessados. A presença de microfósseis em depósitos sedimentares tem sido amplamente negligenciada nas propostas de salvamento paleontológico apresentadas aos órgãos competentes (IBAMA, DNPM, etc.). Um bom exemplo de recuperação bem-sucedida de microfósseis pode ser vista no salvamento paleontológico realizado durante a implantação da UHE Belo Monte (TOMASSI et al., 2015). Este é um importante ponto a ser enfatizado em futuras propostas e a inclusão destas amostragens 
e análises no rol de atividades a serem realizadas por esta equipe teve como intuito (i) demonstrar que sempre pode haver a presença de restos de algum tipo de microrganismo em depósitos sedimentares e, com isso, (ii) estimular a inclusão da prospecção deste tipo de fóssil nas propostas futuras a serem encaminhadas aos órgãos pelas empresas. Os restos microscópicos de organismos pretéritos são tão, ou mais, importantes que os macroscópicos nas reconstruções dos ambientes, ecossistemas e climas do passado, pois eles normalmente representam uma amostragem mais significativa das biotas do passado, dada a sua abundância e representatividade nos depósitos sedimentares.

Recentemente, o material paleobotânico obtido da argila laminada (Ponto 019) foi objeto de estudo em projeto de mestrado desenvolvido junto ao Programa de Pós-Graduação em Geociências da UFRGS, tendo sido descritos e identificados os melhores espécimes. $\mathrm{O}$ resultado foi apresentado em forma de artigo que se encontra no momento em processo de avaliação (GOBO et al., no prelo). Juntamente com a presente contribuição, encerra-se o ciclo do salvamento, por meio da análise e divulgação dos resultados obtidos junto à comunidade através das publicações.

\section{REFERÊNCIAS}

BRASIL. Decreto-Lei n. 4.146, de 04 de março de 1942. Dispõe sobre a proteção dos depósitos fossilíferos. Disponível em: <http://www.dnpm.gov.br/acesso-a-informacao/legislacao/decretos-lei/decretos-lei>. Acesso em: 19 jun. 2017.

. Constituição da República Federativa do Brasil. Promulgada em 5 de outubro de 1988. Brasília, DF: Senado Federal, Centro Gráfico. 1988.

. Lei n. 8.176, de 08 de fevereiro de 1991. Define crimes contra a ordem econômica e cria o Sistema de Estoques de Combustíveis. Brasília, DF: Senado Federal, Centro Gráfico. 1991. Disponível em: <http:/ / www.planalto.gov.br/ccivil_03/leis/L8176.htm>. Acesso em: 19 jun. 2017.

. Departamento Nacional de Produção Mineral. Atribuições do DNPM em matéria de fósseis e sítios de valor paleontológico encontrados em território brasileiro. Parecer normativo, n. 107, de 23 de abril de 2010. Disponível em: <http://www.dnpm.gov.br/acesso-a-informacao/legislacao/pareceres/pareceresproge/2010-107-parecer_proge_107_2010.pdf/view>. Acesso em: 19 jun. 2017.

BRILHA, J. Património geológico e geoconservação. Braga: Palimage, 2005.

EDWARDS, D.; WILLIAMS, D. Rescue palaeontology. Geology Today, v. 27, n. 2, p. 65-69, 2011.

GOBO, W.V.; IANNUZZI, R.; ERTHAL, F., ROBRAHN-GONZÁLEZ, E.M. Primeiro registro de macroflora do Pleistoceno final nas margens do rio Teles Pires, MT, Brasil. Rev brasil. Paleont. [no prelo]

GRAY, M. Geodiversity: valuing and conserving abiotic nature. Chichester: Wiley, 2004

GRAY, M. Geodiversity: developing the paradigm. Proceed. Geologists' Assoc., v. 119, p. 287-298, 2008.

IANNUZZI, R.; ERTHAL, F. Projeto Básico Ambiental (PBA) UHE Teles Pires P.32 - Programa de Investigação, Monitoramento e Salvamento do Patrimônio Fossilífero. In: DOCUMENTO ARQUEOLOGIA E ANTROPOLOGIA LTDA. Relatório Final. São Paulo, 2014. [Inédito]

LACERDA FILHO, J.V.; ABREU FILHO, W.; VALENTE, C.R. et al. Geologia e Recursos Minerais do Estado de Mato Grosso. Escala 1:1.000.000. Goiânia: CPRM, 2004. [Convênio CPRM/SICME]

SHARPLES, C. Concepts and principles of geoconservation. Tasmanian Parks and Wildlife Service web site, 2002. 81p. Disponível em: http://dpipwe.tas.gov.au/conservation/geoconservation/aboutgeoconservation. Acesso em: 27 jul. 2018. 
TOMASSI, H.Z.; ALMEIDA, C.M.; FERREIRA, B.C; BRITO, M.B. et al. Preliminar results of paleontological salvage at Belo Monte Powerplant construction. Brazil. J. Biol., v. 75, n. 3, p. 277-289, 2015. doi. org/10.1590/1519-6984.1714BM.

WILLIAMS, D.; EDWARDS, D. Moulding and cast replication of outcrops: a tool in geoconservation.

Proceed. Geologists' Assoc., v. 124, p.648-652, 2013.

Data de submissão: 16/abr./2018

Data de aceite: 02/ago./2018 